\title{
Vampyroteuthis infernalis e a cultura Nobrow contemporânea
}

\author{
Vampyroteuthis infernalis na cultura Nobrow contemporânea
}

Vampyroteuthis infernalis y la cultura contemporánea Nobrow

Janaína Quintas Antunes

Pontifícia Universidade Católica de São Paulo - PUCSP $<$ tcheina@hotmail.com>

\section{Resumo}

Vampyroteuthis Infernalis, a "lula vampira do inferno", é o instrumento pelo qual Vilém Flusser e Louis Bec espelham a filogênese humana, merguIhando profundamente em um abismo (literal e figurativo) oceânico e filosófico que nos separa deste animal neste ensaio, nesta fábula paranaturalista; e ele também será 0 espelho utilizado para refletirmos e compreendermos a cultura Nobrow: um novo conceito, uma nova estética contemporânea, um novo momento na história cultural do século XXI; justamente através da leitura crítica deste livro tão particular. Esta obra foi escolhida para auxiliar na compreensão da comunicação, da cultura Nobrow, caracterizada exatamente como a cultura do inclassificável na era da cibercultura. Como Nobrow, compreendemos todo tipo de produção ou produto cultural contemporâneo que não se encaixa em nenhuma categoria, em nenhum padrão, em nenhuma regra. 0 século XXI começou com uma forte tendência a essa estética cultural; é possível observar que a cultura atual não segue um horizonte único, um estilo único constitutivo de uma época. 0

\section{Abstract}

Vampyroteuthis Infernalis, the "vampire squid from hell", is the instrument by which Vilém Flusser and Louis Bec mirror human phylogenesis, plunging deeply into an oceanic and philosophical abyss (literal and figurative) that separates us from this animal in this essay, in this paranaturalist fable; and it will also be the mirror used to reflect and understand Nobrow culture: a new concept, a new contemporary aesthetic, a new moment in the cultural history of the 21 st century; precisely through the critical reading of this very particular book. This work was chosen to assist in the understanding of communication, of the Nobrow culture, characterized exactly as the culture of the unclassifiable in the cyberculture era. Like Nobrow, we understand all types of contemporary cultural products or products that do not fit into any category, any standard, any rule. The 21 st century began with a strong tendency towards this cultural aesthetic; it is possible to observe that the current culture does not follow a single horizon, a unique style constituting

\section{Resumen}

Vampyroteuthis Infernalis, el "calamar vampiro del infierno", es el instrumento mediante el cual Vilém Flusser y Louis Bec reflejan la filogénesis humana, sumergiéndose profundamente en un abismo oceánico y filosófico (literal y figurativo) que nos separa de este animal en este ensayo, en esta fábula paranaturalista ; y será también el espejo utilizado para reflejar y comprender la cultura Nobrow: un nuevo concepto, una nueva estética contemporánea, un nuevo momento en la historia cultural del siglo XXI; precisamente a través de la lectura crítica de este libro tan particular. Este trabajo fue elegido para ayudar en la comprensión de la comunicación, de la cultura Nobrow, caracterizada exactamente como la cultura de lo inclasificable en la era de la cibercultura. Como Nobrow, entendemos todo tipo de productos culturales contemporáneos o productos que no encajan en ninguna categoría, ningún estándar, ninguna regla. El siglo XXI comenzó con una fuerte tendencia hacia esta estética cultural; se puede observar que la cultura actual no sigue un horizonte único, un estilo único que constituye 
presente cultural escapa a categorizações, e o inclassificável hoje se chama Nobrow.

Palavras-chave: Flusser, Nobrow, Vampyroteuthis Infernalis an era. The cultural present escapes una época. El presente cultural escapa categorization, and the unclassifiable a la categorización, y lo inclasificable today is called Nobrow. hoy se llama Nobrow.

Keywords: Flusser, Nobrow, Vampyro- Palabras clave: Flusser, Nobrow, teuthis Infernalis Vampyroteuthis Infernalis

\section{Introdução}

Vampyroteuthis infernalis, a "lula vampira do inferno", é o instrumento pelo qual Vilém Flusser e Louis Bec espelham a filogênese humana, mergulhando profundamente em um abismo (literal e figurativo) oceânico e filosófico que nos separa desse animal nesse ensaio, nessa fábula paranaturalista; e ele também será o espelho utilizado para refletirmos e compreendermos a cultura Nobrow: um novo conceito, uma nova estética contemporânea, um novo momento na história cultural do século XXI; justamente através da leitura crítica desse livro tão particular (FLUSSER; BEC, 2011).

Flusser reflete nessa obra, através do Vampyroteuthis, sobre o humano e o não humano, não somente sobre nossos traços vampyrotêuthicos como também sobre os traços humanos deste. Uma escolha apropriada, considerando que somos ambos frutos cheios de defeitos de uma coincidência absurda, como descreve o autor. Assim como nós nos afastamos de nosso ambiente original para caminharmos sob a superfície dos continentes, ele também se aprofunda no abismo escuro oceânico, afastando-se da luz. Todavia, somos o reverso um do outro, o caminho espelhado de uma evolução semelhante, mas em direções contrárias. Distanciamo-nos da condição humana, estabelecendo uma perspectiva singular, nos conduzindo à nossa própria estrutura existencial, conjecturada pelo ponto de vista mais distante possível.
Esse salto de um mundo para o outro nos proporciona a metáfora necessária para que essa ficção filosófica alcance uma compreensão incrivelmente fascinante e única da nossa fenomenologia pós-humanista, da nossa pós-história. Justamente por essa possibilidade proporcionada, esta obra foi escolhida para auxiliar na compreensão da comunicação, da cultura Nobrow, caracterizada exatamente como a cultura do inclassificável na era da cibercultura. Como Nobrow, compreendemos todo tipo de produção ou produto cultural contemporâneo que não se encaixa em nenhuma categoria, em nenhum padrão, em nenhuma regra. $\mathrm{O}$ século XXI começou com uma forte tendência a essa estética cultural; é possível observar que a cultura atual não segue um horizonte único, um estilo único constitutivo de uma época. O presente cultural escapa a categorizações, e o inclassificável hoje se chama Nobrow.

Não é possível alcançar tal compreensão sob as lentes do ser humano pós-moderno. Precisamos nos afastar, adquirir nova perspectiva, para somente assim compreendermos uma nova cultura que não se baseia mais nos conceitos que temos em mãos.

Nas palavras do próprio autor:

Nela (zoologia vampyrotêuthica), reconhecemos vários traços da nossa própria existência no mundo. Outros traços nossos, embora reconhecíveis, são nele curiosamente deformados. 
Destarte podemos iniciar um jogo com espelhos deformadores, um oposto ao outro. Um jogo de reflexão, durante o qual vamos descobrindo nossa própria estrutura existencial de um ponto de vista que nos é muito distante. Trata-se, no entanto, de uma reflexão não transcendente. Embora o Vampyroteuthis esteja muito afastado de nós, está não obstante conosco no mundo. [...] De maneira que nos convida à reflexão imanente ao mundo. O resto deste ensaio será "fábula"; tentativa de criticar a nossa existência vertebrada do ponto de vista molusco. Como toda fábula, esta também tratará, sobretudo, do homem, embora um "animal" lhe sirva de pretexto. (FLUSSER; BEC, 2011, p. 19).

Reconhecemos uma existência comparável à nossa ao dar de frente com um mundo diferente, nos transportando do nosso mundo para o do Vampyroteuthis. É exatamente uma metáfora, transferência de mundo para mundo.

O Vampyroteuthis é o nosso oposto, não apenas filogeneticamente, como também geográfica e existencialmente. Ele é o objeto de estudo desta obra, já que, por ser o homem um ente mergulhado no mundo e condicionado pelo mundo, não pode pois falar sobre o mundo (FLUSSER; BEC, 2011, p. 29).

Flusser desde o início do livro afirma que devemos nos libertar dos modelos, fator este fundamental para a compreensão do $\mathrm{No}$ brow. Ele defende que abandonemos o ideal da objetividade em prol de outro tipo de método científico, métodos intersubjetivos:
A ciência é interessante, precisamente porque me diz respeito. É ela função humana, tanto quanto a respiração: interessa existencialmente. Uma ciência integralmente objetiva seria desinteressante, desumana. A busca da objetividade científica está se revelando, sempre melhor, não como busca da "pureza", mas como loucura perniciosa. (FLUSSER; BEC, 2011, p. 30).

O Vampyroteuthis responde a essa finalidade do autor. Por um lado, está extremamente afastado de nós filogeneticamente, o que nos permite uma objetividade científica maior do que se estudássemos animais mais próximos de nós, como por exemplo, chimpanzés. Mas o Vampyroteuthis também nos permite a intersubjetividade, pois é a ponta contrária da evolução rumo à verticalidade que permitiu a ambos, homem e Vampyroteuthis, superar a "animalidade".

Trata-se de uma inversão de eixo idêntica à nossa própria inversão vertical, a qual fomos obrigados a realizar quando abandonamos as copas das árvores em prol da tundra, mas de inversão em sentido oposto à nossa. Quando erguemos nosso corpo, libertamos os olhos para os horizontes, e as mãos para a apreensão de objetos. Quando os Cephalopoda se ergueram, os seus órgãos de percepção, de locomoção e de ataque se deslocaram rumo ao chão, cercaram a boca, e entraram em contato imediato com o cérebro que cerca a boca. São suas verticalidades antipodais contrapostas à horizontalidade "normal" dos organismos. (FLUSSER; BEC, 2011, p. 31-32). 
Além de sua gênese, Flusser também discorre sobre o mundo do Vampyroteuthis (seu modelo, o abismo e sua existência) e sobre sua cultura (seu modo de pensar, sua vida social e sua arte), além de refletir sobre sua emergência. Sempre pela analogia.

Assim sendo, iniciemos com nossas ponderações sobre o Vampyroteuthis, sobre essa obra de Flusser e Bec; para a partir dessas ponderações, podermos introduzir, analisar e compreender a gênese da cultura Nobrow.

\section{0 mundo do Vampyroteuthis infernalis}

Ao falar sobre seu mundo, o autor inicia a análise do modelo justificando-a pelo fato de que quem analisa um organismo, analisa sua ontogênese e sua filogênese, o seu "destino" individual e coletivo (FLUSSER; BEC, 2011, p. 48), objetivo também partilhado por esta leitura crítica. Flusser fala sobre o surgimento de sua existência guerreira, suicida e canibal, de sua existência pós-messiânica, de como sua evolução abriu um novo caminho, no além do amor, rumo à morte. De evolução da vida, passa ela a ser evolução da morte. Modelo difícil e perturbador, este (FLUSSER; BEC, 2011, p. 50).

Em sua analogia dos modelos do Vampyroteuthis e do homem, Flusser afirma que nossa meta é fundir-nos no outro, a fim de transcendermos a morte. A sua meta é de fundir-se no outro a fim de poder devorá-lo e suicidar-se (FLUSSER; BEC, 2011, p. 52).

Quanto ao abismo, o autor inicia seu exame com um debate crítico e moral sobre a grande e antiga questão de hereditariedade versus ambiente, para assim poder filosofar sobre o organismo espelhando este último (no caso do Vampyroteuthis, o abismo oceânico), assim como o ambiente espelha o organismo. Ele coloca como o abismo é paraíso para o Vampyroteuthis e como é enxergado como inferno pelo humano, de acordo com o ser que esse ambiente (da mesma maneira como aconteceria em relação a qualquer outro ambiente) espelha. São dois modelos do "mesmo" ambiente que se entrechocam. Não é que um dos modelos seja "verdadeiro" e o outro "falso". Ambos são verdadeiros no sentido de refletirem determinados seres-no-mundo (FLUSSER; BEC, 2011, p. 65).

Ao mesmo tempo, Flusser também avalia o abismo sob o olhar da ciência "objetiva", com essa verificando que:

[...] ambos os modelos são "falsos". O abismo não pode ser infernal, já que se o fosse, o Vampyroteuthis não teria sobrevivido. E não pode ser paradisíaco, já que se o fosse, o Vampyroteuthis não teria tido a necessidade de desenvolver um cérebro complexo para poder viver nele. $\mathrm{O}$ ponto de vista objetivo exige um terceiro modelo, igualmente abstrato. (FLUSSER; BEC, 2011, p. 65).

$\mathrm{Na}$ ideia de analisar o ambiente do Vampyroteuthis para refletir a existência do homem é justamente habituar-nos ao inabitual, visto que não podemos habitar o inabitável. Por meio desse espelhamento podemos contemplar o que nos é habitual como se fosse inabitual, podemos reidentificar o inabitual que somos. Conforme veremos mais adiante, esse é o maior desafio do Nobrow, pois ele foge do habitual, se torna inabitual, o que causa diversos problemas de identificação. 
Na continuação da discussão sobre ambiente vem uma discussão sobre a existência do Vampyroteuthis iniciada pela afirmação de que existência é um "estar no mundo":

[...] há sempre um sujeito relacionado com objetos, e objetos relacionados com um sujeito, e que a "realidade" é precisamente tal relacionamento [...], toda modificação do objeto implica modificação do relacionamento. Modificação que se espelha "secundariamente", tanto no sujeito quanto no objeto. Por exemplo: quando os primatas se ergueram do chão, é que determinado relacionamento foi modificado. Isto se espelha como modificação do organismo primata, e como modificação do ambiente humano. (FLUSSER; BEC, 2011, p. 66).

A estrutura do mundo espelha a estrutura do organismo. Assim, com uma modificação no nosso ambiente tão grande quanto a introdução do ciberespaço, nós mudamos e nosso modo de produzir muda - e faz surgir o Nobrow. O claro delineamento de tempo da cultura, da evolução da cultura, se esvanece com o aparecimento da cibercultura, porque esta última torna possível que um artista seja influenciado por culturas e movimentos completamente desvinculados, completamente fora de uma determinada ordem de tempo, ou ordem geográfica. $\mathrm{O}$ artista pode ser conjuntamente influenciado por um artista neolítico da Ásia e por um expressionista africano. Somos arrebatados por influências infinitas, muitas vezes não sendo capazes de dizer pessoalmente o que eram ou de onde vieram, por conseguinte criando uma grande dificuldade para nomear-nos ou integrar-nos a único movimento, porque hoje em dia nós somos atemporais e ageográficos. Uma total mudança de estrutura, reflexo da mudança da estrutura do ambiente.

Dentro da pauta da existência, Flusser coloca a questão dos objetos, da infernalidade do Vampyroteuthis e introduz a ideia de cultura.

Tanto o mundo do Vampyroteuthis quanto o nosso estão baseados nas nossas relações com objetos, nas nossas manipulações de objetos. Não importa o que apreendemos, nós e o Vampyroteuthis, pode ser apalpado, "concebido", "definido", é "objeto". E tudo o que pode ser destarte "contatado" por apalpamento dos seus contornos é ipso facto modificável (FLUSSER; BEC, 2011, p. 70-71).

Ou seja, ambos temos a capacidade de modificar o mundo, e de tal modo entramos na conceitualização de nossas culturas, humana e vampyrotêuthica, pois se definirmos cultura por "modificação deliberada do mundo por um sujeito”, então encontraremos a cultura presente tanto no programa dos homens quantos dos Vampyroteuthes.

Para os homens o mundo a ser modificado consiste em problemas que barram o caminho, e "cultura" é a remoção de problemas para abrir caminhos. Cultura, em tal significado, é empresa emancipadora, e é um "projeto" contra objetos. Para o Vampyroteuthis, o mundo a ser modificado consiste em impressões que se precipitam sobre ele, e "cultura" é incorporação de impressões para digeri-las. Cultura, em tal significado, é empresa integradora, e é uma "injeção" de objetos. A cultura no significado do humano é remoção de "natureza", a cultura no significado 
vampyrotêuthico é crítica da "natureza”. (FLUSSER; BEC, 2011, p. 71).

Ambas as nossas existências - a dúvida cartesiana humana e a admiração aristotélica vampyrotêuthica - são consequências de uma ruptura entre sujeito e objeto.

Quando, há algumas dezenas de milhares de anos, o clima se refrescou, as árvores rarearam e a paisagem se transformou em Tundra. Os primatas habitantes das copas das árvores viam-se no "espaço vazio" da estepe. Seus olhos, em vez de perceberem folhagens, passaram a perceber horizontes, e seus dedos, em vez de apalparem ninhos, passaram a apalpar os ossos e as pedras no solo da tundra. Em tal mundo estranho, no qual os primatas eram estrangeiros, passaram eles a manipular os ossos e as pedras, a fim de transformá-los em "mediações" com o mundo estranho, em "instrumentos" para superar sua alienação do mundo. Os primatas passaram a ser homens. (FLUSSER; BEC, 2011, p. 73).

Obviamente não sabemos sobre a ruptura similar do Vampyroteuthis, mas sabemos que, enquanto o homem assumiu o papel ativo quando se assumiu sujeito de seu mundo, o Vampyroteuthis assumiu o polo passivo de sua relação com o mundo.

O mundo não é, como para nós, o polo oposto que é preciso apanhar ativamente. O mundo, para ele, é polo oposto que é preciso sorver apaixonadamente. [...] Se nós, os homens, projetarmos nossa existência para o "além" do mundo, teremos, do outro lado do mundo, um sujeito ativo transcendente, Deus. Se o Vampyroteuthis projetar destarte sua existência, terá ele, do outro lado do mundo, um sujeito passional transcendente, o diabo. (FLUSSER; BEC, 2011, p. 74).

Deste modo, conduzimo-nos à conclusão de que não somos complementares, somos opostos, espelhos. Toda tentativa de transformar o Vampyroteuthis em complementaridade humana é traição da existência humana. Romantismo perigoso. Não adianta querer minimizar: o Vampyroteuthis é o nosso inferno (FLUSSER; BEC, 2011, p. 77).

E assim entramos na cultura do Vampyroteuthis. Flusser inicia discorrendo sobre seu modo de pensar.

\section{A cultura do Vampyroteuthis infernalis}

O Vampyroteuthis reflete. Como um ser extremamente complexo, se não refletisse não teria existido, já que a reflexão tem um papel único na evolução da vida. A reflexão é necessária para a sobrevivência de organismos supercomplexos. Assim como no homem, a capacidade reflexiva é como uma base inata para a elaboração de filosofias adquiridas. Base "natural" para o fenômeno cultural da filosofia (FLUSSER; BEC, 2011, p. 81). Desta maneira, também já podemos afirmar que o Vampyroteuthis é um ser histórico, produtor de cultura. Tal conclusão já está contida na premissa de que o Vampyroteuthis é um ente que reflete. Porque "reflexão" significa não apenas controle do processamento de dados, mas igualmente controle do armazenamento de dados (FLUSSER; BEC, 2011, p. 83-84). 
Toda reflexão é produtora de história. Agora, enquanto o homem armazena sua história em objetos (livros, quadros, edificações etc.) e tem dificuldade em conceber história sem estes objetos, o Vampyroteuthis não produz tais objetos com tais objetivos, não produz uma "cultura objetiva", o que nos dificulta a admissão de sua historicidade.

O Vampyroteuthis nos obriga a repensar não apenas o conceito de história, como também nossa própria historicidade. Seu comportamento sugere que seu empenho histórico é o armazenamento de dados adquiridos diretamente nos sistemas nervosos dos membros da espécie, e que o método de tal armazenamento é a transmissão dos dados adquiridos por um membro da espécie aos outros. Não temos modelo para tal historicidade dialógica, que não passa pela mediação de objetos. Não temos modelo de uma história sem cultura objetiva. Mas o Vampyroteuthis nos oferece a oportunidade de elaborar tal modelo. Permite que contemplemos a história humana do seu ponto de vista. Que façamos crítica vampyrotêuthica da história humana. (FLUSSER; BEC, 2011, p. 84-85).

Essa crítica vampyrotêuthica nos permitirá refletir sobre e explicar a história e cultura Nobrow contemporâneas.

Os objetos da cultura humana servem como meio de comunicação entre indivíduos, como portadores de mensagens, mas estes também ganham autonomia pois podem reconstituir a história humana, podem permitir isso a um observador externo que analisar objetos informados pelos homens.
Em tese, pois, o homem seria capaz de uma comunicação intersubjetiva, e, portanto, de verdadeira historicidade. Mas o homem é impedido de elaborar uma verdadeira história dialógica pela presença de numerosos objetos que se encontram na superfície da Terra e constituem obstáculos a comunicação intersubjetiva. O homem se vê obrigado a transformar tais obstáculos em canais da comunicação, a modificá-los. Sua história é, em grande parte, tal modificação de objetos. Pois isto vai desviando a atenção e a intenção humana dos outros para os objetos. O propósito da história humana deixa de ser informar os outros com dados adquiridos, mas o de informar objetos. (FLUSSER; BEC, 2011, p. 87).

Esse propósito torna a história humana facilmente constatável pelo crítico vampyrotêuthico. Mas precisamente por ser assim objetivamente constatável, a história humana não é história verdadeira [...] falta-lhe o característico da verdadeira história, que é o armazenamento controlado de dados adquiridos na memória dos participantes do processo (FLUSSER; BEC, 2011, p. 87-88). Todavia, isso muda no advento da cibercultura, como analisaremos mais adiante. Flusser levanta a questão da possibilidade de existência de outro tipo de cultura, da possibilidade de existência de uma cultura vampyrotêuthica. E se essa cultura existir, seria ela decifrável pelos homens? Uma questão compartilhada pela cultura Nobrow.

Mas voltando à cultura vampyrotêuthica:

Devemos admitir que o Vampyroteuthis não fabrica objetos, com exceção 
das nuvens de sépia que modela. Nesse sentido, não faz cultura. Por outro lado, devemos admitir que o Vampyroteuthis contrai determinadas glândulas para secretar determinados sucos, e que tais sucos são portadores de mensagens. (FLUSSER; BEC, 2011, p. 88).

Assim, Flusser pondera que as nuvens de sépia produzidas assumem as formas mais variadas e suportam as mensagens mais diversas. Essas mensagens antes com um caráter apenas defensivo, direcionado apenas aos agressores, agora são direcionadas também aos outros Vampyroteuthes. São seu meio de comunicação intersubjetiva. $\mathrm{O}$ autor analisa as glândulas secretoras do Vampyroteuthis, que nada mais são que os portadores de sua história:

[...] sabemos que as mensagens podem ser muito abstratas (glândula gelatinosa), muito complexas (coloração da pele), e "artísticas", isto é, mentirosas e altamente conotativas (sépia). Isto nos permite captar o clima da cultura vampyrotêuthica, senão o seu significado. (FLUSSER; BEC, 2011, p. 91).

Do mesmo modo que o Vampyroteuthis, nós também codificamos nossas mensagens, de maneira que possam ser captadas apenas por quem possui a chave. Nós codificamos de modo que o receptor possa descobrir a chave. O Vampyroteuthis codifica escondendo a chave, como os emissores de mensagens secretas (FLUSSER; BEC, 2011, p. 91). A cultura Nobrow o faz do mesmo modo, mas o faz de maneira desproposital.
O Vampyroteuthis visa enganar seus parceiros. Usa media fluidos, efêmeros e altamente conotativos para que seus parceiros não possam criticar as mensagens. Visa a seduzir ou violentar seus parceiros para que estes armazenem informações sem criticá-las. A cultura do Vampyroteuthis é um conjunto de artifícios, de estratégias, de "demagogias". É conspiração de todos contra todos. (FLUSSER; BEC, 2011, p. 91).

A comunicação e a cultura Nobrow não são criticáveis, mas isto não se dá propositalmente.

Nobrow diz respeito ao isolamento local de artistas, porém unidos internacionalmente via ciberespaço. Nobrow é a união de tudo na indeterminação; é a possibilidade de categorização de obras que na cultura contemporânea são inclassificáveis. Nobrow abrange obras e movimentos indefiníveis disseminados por todos os continentes por meio do ciberespaço. (ANTUNES, 2020, p. 20).

A diferença entre as comunicações vampyrotêuthica e humana é que a comunicação humana visa ao deciframento correto, e a comunicação vampyrotêuthica visa ao deciframento errado. Isto em tese. Porque há comunicação do tipo vampyrotêuthico também na cultura humana (FLUSSER; BEC, 2011, p. 93). Justamente o que acontece na cultura Nobrow. A comunicação Nobrow é vampyrotêuthica acidentalmente; ela gostaria de não ser, mas não consegue deixar de sê-lo. É uma cultura humana pois almeja desesperadamente ser decifrada, mas não consegue deixar de ser vampyrotêuthica, já que seus pares não conseguem criticá-la, analisá-la, 
categorizá-la ou decifrá-la. É a conspiração do mundo cibercultural nela mesma.

Ao entrar na questão da vida social, Flusser analisa que as estruturas sociais "pretensamente naturais" humanas, como família, povo, nação; são na realidade culturalmente determinadas. De maneira que o engajamento humano se dirige mais contra as estruturas evoluídas ao longo da história, e menos contra estruturas inatas (FLUSSER; BEC, 2011, p. 104). No Vampyroteuthis acontece o contrário, as estruturas sociais geneticamente programadas são relativamente mais fortes. É ele ente que se "reconhece nos outros" mais instintivamente que o homem. De maneira que seu engajamento se dirige mais contra sua própria "natureza", e menos contra sua cultura (FLUSSER; BEC, 2011, p. 104).

A reflexão final de Flusser sobre o comportamento social do Vampyroteuthis é justamente que ele não é o oposto ao nosso.

[...] reconhecemos, nos motivos e nos gestos sociais vampyrotêuthicos, os nossos próprios motivos e gestos mais nobres. Ao contemplarmos o comportamento social vampyrotêuthico, reconhecemos que seus valores estão no núcleo do nosso próprio comportamento. Que o Vampyroteuthis se esconde no fundo do nosso próprio pensamento político, e que a ética humana é, em seu próprio núcleo, vampyroteutha. E se analisarmos os nossos próprios modelos, sejam políticos ou parapolíticos, acabaremos desenterrando o Vampyroteuthis. (FLUSSER; BEC, 2011, p. 107).

Portanto, o Vampyroteuthis realmente não é o oposto do homem, mas sim o lado re- primido deste. Assim como o homem também é o lado reprimido do Vampyroteuthis.

\section{Arte Nobrow e Arte Vampyrotêuthica}

O termo Nobrow faz referência aos termos highbrow e lowbrow, de maneira a representar o conceito de cultura sem uma qualificação de lowbrow ou highbrow, sem um direcionamento específico a determinado tipo de público, ou à determinada área do conhecimento. Tal cultura não é nem popular, nem erudita; nem de certo estilo, ou de outro; uma cultura não categorizada.

Nobrow foi a expressão cunhada pelo jornalista John Seabrook (2001) e posteriormente utilizada por Peter Swirski (2005) para caracterizar esta nova tendência da cultura: a tendência de uma cultura independente de hierarquias sociais.

Essa mistura de tendências highbrow e lowbrow deu origem ao que seria chamado de hibridismo - e não apenas a um de diversos fatos que seriam chamados de hibridismo -, e este impulsionaria o surgimento da estética cultural denominada Nobrow ou, poderíamos dizer, uma cultura sem categorização. Nobrow é a evolução do hibridismo vinda da interatividade típica da cibercultura, caracterizada como uma cultura interativa digital em tempo real.

A expressão Nobrow faz alusão a bens culturais dificilmente classificados. Nobrow está surgindo como a cultura do século XXI, nascida sob condições tecnológicas e culturais específicas da contemporaneidade. Mais precisamente, é o inclassificável na era da cibercultura [...], consequência da interatividade mundial. (ANTUNES, 2020, p. 17). 
Objetos culturais inclassificáveis, em geral, são isolados - ainda que em bunkers glocais que sintetizam e simbolizam, de modo exemplar e espargido, ao nível do processo civilizatório, a tendência contemporânea a um "cerramento" material pleno em regime de "abertura" midiática "total" para o mundo e para a alteridade (TRIVINHO, 2008, p. 22) -, justamente por essa sua própria natureza, eles acabam não conseguindo integrar-se a um único movimento. Esses objetos podem ter existido há milênios, mas somente os surgidos na contemporaneidade se integram à cultura Nobrow, já que essa se originou exclusivamente tendo em vista a vigência da cibercultura, o que torna a estética Nobrow completamente típica deste milênio.

Por certo, os objetos culturais Nobrow não estão necessariamente vinculados ao digital e ao interativo; eles não estão obrigatoriamente no ciberespaço. O Nobrow não necessariamente passa pelo ciberespaço, entretanto, ele tende a passar pela rede virtual. Contudo, cada obra Nobrow foi influenciada pelos traços da cibercultura, cada uma recebeu, por meio do ciberespaço, influências diretas ou indiretas de outras obras e artistas do mundo inteiro.

O século XXI começou demonstrando tendência à cultura Nobrow, altamente disseminada. Nesse contexto, as artes e a cultura não estão sendo propriamente classificadas e nomeadas, entretanto não há divulgação ou conhecimento desse termo, não havendo também consciência desse fato. Artistas e movimentos culturais se classificam erroneamente em movimentos ultrapassados não mais vigentes, ou simplesmente deixam de se classificar, e não conseguem, assim, se encaixar.
Nobrow é a estética dominante deste novo século, e como tal marca o novo período histórico da cultura atual. A sociedade e a cultura se encontram em nova fase, que não se encaixa mais dentro das definições pós-modernistas ou de outras quaisquer. Nobrow se colocaria como categoria substitutiva para pensar esse novo tempo.

Nobrowé o período cultural mais livremente criativo, já que a sua ausência de categorização faz com que ele não esteja delimitado pelos padrões acadêmicos. Nobrowé uma cultura que funciona em diversos sentidos e anda em diversas direções, uma cultura livre e não hierárquica. Em suma, Nobrow são todas as artes e todos os artistas influenciados e inspirados por todas as artes e todos os artistas de todo o mundo. (ANTUNES, 2020, p. 65).

Há a necessidade de se aprender a analisar o sistema cultural de acordo com essa estrutura atual, pois isso se faz impossível se nos basearmos em estruturas que não se aplicam mais. A estética da cultura Nobrow nos traz imensas possibilidades, mas se mostra muito mais densa de ser trabalhada ou analisada do que qualquer estética anterior já foi. Contudo, isso não é motivo justificável, há uma enorme e presente necessidade de estabelecer parâmetros, de nomear as fundações estéticas e culturais contemporâneas, assim como também há a necessidade de criar uma perspectiva dos caminhos e necessidades da cultura do século XXI, especialmente dentro do emergente e desconhecido movimento do Nobrow.

A história cultural do século XXI não está sendo profundamente escrita, caracte- 
rizada, e não deve continuar prosseguindo sem rumo. Somos seres históricos, não podemos deixar a característica única e excepcional de nossa contemporaneidade cair no esquecimento.

Flusser discute justamente que no engajamento de ambos, homem e Vampyroteuthis, contra o esquecimento - já que ambos são seres históricos - há diferentes métodos de armazenamento. $\mathrm{O}$ homem busca transmitir informações por meio de objetos, ele confia na permanência relativamente imortal destes; além de também possuir a transmissão de informações por meio genético, pelo ovo. Já para o Vampyroteuthis, o único armazém confiável de informações é o ovo. A informação genética de ambos sobreviverá aos objetos, sobreviverá inclusive à espécie, mesmo que de forma alterada.

Quando todas obras humanas tiverem sido reduzidas a pó há muito tempo, a informação genética humana continuará sendo transmitida de geração a geração, embora possivelmente por espécie evoluída da humana. De maneira que o problema do engajamento histórico é elaborar métodos que permitam armazenar dados adquiridos na mesma memória que também armazena os dados inatos. Confiar na permanência da espécie e do seu futuro desenvolvimento, e não na permanência do mundo objetivo. Por certo: tais métodos de armazenamento e de transmissão podem recorrer a objetos. Mas tais objetos não serão armazéns, serão canais de transmissão, "media". (FLUSSER; BEC, 2011, p. 109-110).
O Vampyroteuthis também se utiliza das nuvens de sépia como objetos, a diferença é apenas o fato de o homem confiar um pouco mais na permanência dos objetos. O homem é ente que busca a sua imortalidade nos objetos e é por isso que se exprime neles. E o Vampyroteuthis é ente que busca sua imortalidade no outro, e é por isso que se exprime dentro do outro por meio de objetos (FLUSSER; BEC, 2011, p. 110).

São dois gestos articuladores diferentes, com efeito, são duas artes diferentes. Além do gesto articulador específico da cultura Nobrow. Nobrow é a articulação do mundo, de cada obra e de cada artista (isolado localmente) na internacionalização das culturas de todos os lugares através da comunicação providenciada pela tecnologia; é a confluência global de características culturais. Reiterando, Nobrow é um fenômeno simultaneamente local e internacional, situado na era da cibercultura, que utiliza o ciberespaço como um meio para a internacionalização da cultura.

Na articulação humana, vivência e objeto são indissolúveis um do outro:

Tudo o que o homem vivencia é vivenciado "para" determinado objeto: para o mármore, para determinada língua falada ou escrita, para sons musicais, para a fita de celulose. E todo objeto que o homem encontra no seu caminho rumo à morte contém implicitamente as categorias que permitem articular determinadas vivências: determinado sentimento, pensamento, valor, desejo. Não é que o homem passe primeiro por uma vivência qualquer, e depois procure por um objeto apropriado para ele exprimi-la. O homem viven- 
cia, desde já, em função de determinado objeto. Vivencia como escultor de mármore, como orador ou escritor português, como músico, como produtor de filmes. Os objetos, sejam eles "materiais" ou "imateriais", sejam eles pedras e ossos ou números e letras, modelam toda vivência humana (FLUSSER; BEC, 2011, p. 111).

A arte humana é o modo do homem transmitir sua vivência sobre o objeto de sua vocação. Ele se realiza como artista, escultor, escritor etc.; ao mesmo tempo que se imortaliza. Já o Vampyroteuthis não precisa necessariamente de objetos externos, porque, esse ponto ao qual a humanidade demorou tanto em sua evolução para chegar, já está embutido em sua natureza corpórea. Enquanto a matéria-prima da arte humana é o objeto, a matéria-prima da arte Vampyrotêuthica é a sociedade.

O Vampyroteuthis não é provocado por objetos. O seu interesse existencial não é desviado pelos objetos: dirige-se sempre ao outro. [...] Os seus tentáculos não são freados pela nuvem de sépia, como são os dedos humanos pela pedra, [...] tentáculos e chromophorios transpassam o objeto. Não "fazem", "perfazem”. Sua criação não é "feita", mas "perfeita”. Por isso, ao criar, não vivencia a perfídia do objeto, mas a perfídia do outro. [...] Para o Vampyroteuthis a memória do outro é o que para nós são pedra e língua. [...] É durante a violação do outro que o Vampyroteuthis vai se realizando. [...] Tal feedback entre emissor e receptor, tal diálogo, é a essência da arte do Vampyroteuthis. (FLUSSER; BEC, 2011, p. 114).
Justamente após explicar detalhadamente o processo criativo vampyrotêuthico, Flusser chega à conclusão de que esse diálogo é eterno, tanto quanto a informação guardada no ovo.

O resultado de tal processo criativo é que doravante há um modelo para captar a vivência inaudita, e que tal modelo está doravante guardado na memória do copulado. A informação adquirida foi destarte incorporada ao diálogo vampyrotêuthico, e o foi para sempre. (FLUSSER; BEC, 2011, p. 115).

Essa imortalidade é buscada pelo Vampyroteuthis através da modelação epistemológica, estética e ética do outro; ela é buscada pela violência exercida no outro.

O processo criativo no Vampyroteuthis é o método pelo qual modelos novos de sensação, de conhecimento e de valor são articulados e transmitidos aos outros, que são violentados por sedução ou por mentiras, para armazená-los. A arte vampyrotêuthica é uma série de artifícios, graças aos quais a sociedade vampyrotêuthica é violentada para admitir determinados modelos, transmitidos pelo intermédio de objetos efêmeros e desprezados. (FLUSSER; BEC, 2011, p. 117).

Essa não é apenas uma definição do processo criativo vampyrotêuthico, como também o é do processo Nobrow.

Por certo: o processo criativo vampyrotêuthico é radicalmente diferente do humano: é gesto diferente e tem 
propósito diferente. No entanto, sua consideração provoca duas reações opostas. De um lado, a nossa própria arte vai revelar, nos seus aspectos antivampyrotêuthicos, caráter pouco lisonjeiro. De outro lado, vamos descobrir uma tendência nítida em nossa própria arte de aproximar-se da arte do Vampyroteuthis. Podemos resumir tal reação da seguinte forma: na medida em que a arte humana diverge da vampyrotêuthica, é ela empresa confusa e indisciplinada, e na medida em que a arte humana vai adquirindo autoconsciência e disciplina, vai convergir com a arte do Vampyroteuthis. (FLUSSER; BEC, 2011, p. 117-118).

Tal tendência de convergência, de aproximação rumo à arte vampyrotêuthica chama-se Nobrow: o conscientizar-se sobre o desprezado e ignorado, o classificar do inclassificável.

A arte humana é pura, porque se esqueceu do seu propósito, que é o de transmitir informações adquiridas rumo a outros, a fim de que estes as armazenem. Mas os homens começam a se tornar conscientes desse esquecimento. Começam a se dar conta de que a história da arte é uma história de mal-entendidos. Começam a fazer "teoria da comunicação", a conscientizar e disciplinar o gesto da arte. A consequência disso é a revolução das comunicações ora em curso, revolução esta que vai reformular o fazer humano todo. No fundo, tal revolução consiste no desvio do interesse existencial, estagnado nos objetos, de vol- ta para o outro. As nossas estruturas comunicacionais vão se transformando fundamentalmente, no sentido de constituírem media efêmeros e transpassáveis, que permitem informar o outro sem passar por objeto. É como se a humanidade, depois de uma volta multimilenar pelo mundo dos objetos, estivesse agora reencontrando o caminho do Vampyroteuthis. Tal vampyroteuthização da nossa arte merece ser considerada um pouco mais de perto. (FLUSSER; BEC, 2011, p. 118-119).

É devida a isso a necessidade do estudo da cultura Nobrow, que é exatamente resultado dessa vampyroteuthização da arte humana. Ela é uma nova teoria da comunicação contemporânea, é essa revolução das comunicações, essa transformação das estruturas comunicacionais resultante dos novos métodos da cibercultura. É esse reformular do fazer humano. Nobrow não é algo necessariamente vinculado ao digital e ao interativo; não está obrigatoriamente no ciberespaço. Contudo, cada obra Nobrow foi influenciada pelos traços da cibercultura; cada uma recebeu influências diretas ou indiretas de outras obras e artistas do mundo inteiro pelo ciberespaço. A estética dos movimentos culturais Nobrow e de suas obras é estabelecida pela articulação social através do ciberespaço. Essas influências, essa confluência global de informações, essa internacionalização de culturas são o reencontro do caminho do Vampyroteuthis.

Flusser explicita em fases o conceito humano de cultura e de artista. Antes da Revolução Industrial, os conceitos de informação, valor e obra eram inseparáveis, eram os três pilares que constituíam o con- 
ceito de "cultura". Com a revolução industrial, objeto e valor vão se separando, e o conceito de "obra" vai se diluindo.

O exemplo mais esclarecedor de tal ruptura do conceito de cultura é fornecido pela imprensa, invenção precursora da revolução industrial toda. É na máquina impressora, e não no livro impresso, que a informação está armazenada, e o valor está no manuscrito, não no livro lido, que passa a ter valor desprezível. [...] A sociedade não se deu conta, na ocasião, do impacto da revolução industrial sobre o processo criador, porque a arte, no sentido restrito, moderno do termo, continuou artesanal, intocada pelos novos métodos de produção, já que estava relegada aos guetos chamados "exposições e museus". (FLUSSER; BEC, 2011, p. 120).

O mesmo acontece em nossa contemporaneidade, no advento da cultura Nobrow: a sociedade não está percebendo a grande mudança nos processos criativos. Nobrow é multilateral, multidimensional, é tudo que é influenciado em amplitude mundial, sendo distribuído de alguma maneira, por qualquer meio, seja pela internet, pela televisão, por diversas mídias. Nobrow é completamente multiaspectal, não é nenhuma área, nenhuma cultura, nenhuma arte específica; é o encontro de todas elas que resulta na produção de objetos culturais inclassificáveis. É a multidimensionalidade de todos os processos de produção. E assim, finalmente, entramos na segunda Revolução Industrial:

A segunda revolução industrial que se inicia atualmente constitui uma nova reformulação dos métodos de produção: informações não são mais armazenadas em ferramentas, mas em programas cibernéticos de aparelhos produtores de ferramentas. Doravante é o programador (o analista e compositor de sistemas) e não mais o ferramenteiro quem informa. $\mathrm{O}$ aparelho vai imprimir a informação automaticamente sobre ferramentas, as quais, por sua vez, vão imprimi-la automaticamente sobre incontáveis objetos. Surge uma maré montante de gadgets cada vez mais baratos que são desprezíveis por serem estereótipos banais, efêmeros, e portadores de informação diluída: "a cultura das massas”. [...] Cultura programada. Cultura sem valor porque produzida automaticamente por aparelhos, [...] leva ao desinteresse pelos objetos. [...] $O$ interesse da sociedade vai se desviando dos objetos para a informação, a qual, no entanto, é inacessível aos consumidores. Está guardada na memória dos aparelhos. Eé transmitida, diluída, não apenas pelos gadgets, mas, sobretudo, pelos canais efêmeros da comunicação de massa. De maneira que a sociedade do futuro imediato será a sociedade do consumo da informação, mais desinteressada no consumo de "bens", de objetos. O interesse vai se desviando da economia para a sociobiologia. Sociedade intersubjetiva: sociedade de Vampyroteuthis. (FLUSSER; BEC, 2011, p. 120-121).

Ou seja, Nobrow.

Até recentemente o homem era um ser que "trabalhava", ou seja, produzia por objetos, transformava o mundo objeti- 
vo; papel este agora desempenhado pelos aparelhos. Os homens deixarão de ser trabalhadores e passarão a ser programadores e receptores de mensagens. A "moral de produção" desaparecerá simultaneamente com a "moral da propriedade" (FLUSSER; BEC, 2011, p. 121). A moral substitutiva que está surgindo é a da elaboração e do consumo de mensagens, da confluência global de informações, do Nobrow. Assim nossa luta existencial não será mais contra objetos, e sim na luta pela preservação e transmissão de informações. Os homens deixarão de ser "operários" e passarão a ser "funcionários de sistemas". Artistas totais funcionando em um totalitarismo programado. Vampyroteuthes (FLUSSER; BEC, 2011, p. 122).

$\mathrm{O}$ autor coloca a fotografia como exemplo mais esclarecedor para a visualização dessa nova ruptura no conceito de cultura:

O valor está na informação impressa sobre a fotografia, que está guardada no protótipo, o "negativo". E tal protótipo foi produzido automaticamente pelo aparelho fotográfico, segundo determinado programa contido no aparelho. O fotógrafo não trabalha, mas funciona dentro do programa do aparelho e reprograma o aparelho. $\mathrm{O}$ propósito do fotógrafo não é o produzir fotografias, mas o de transmitir informações por meio da fotografia. O que fascina o fotógrafo não é o papel fotográfico, o objeto, mas a informação a ser transmitida. O papel fotográfico é para o fotógrafo o que a pele é para o Vampyroteuthis: suporte de mensagens coloridas. (FLUSSER; BEC, 2011, p. 122).
Sim, a nova cultura humana emergente, a comunicação e a arte Nobrow nos mostram aspectos vampyrotêuthicos. Mas há diferenças:

Embora venhamos a desprezar o mundo dos objetos tanto quanto ele (Vampyroteuthis) o despreza, embora tal mundo passe a ser para nós mero conjunto de canais efêmeros de comunicação como o é para ele, emergimos, ao contrário dele, de uma luta contra os objetos que levou dezenas de milhares de anos. Tal luta e as experiências adquiridas durante ela estão guardadas em nossa memória, mas não na sua. Pois travamos tal luta em cooperação com todos os homens contra os objetos, e pudemos sair vencedores apenas graças a tal cooperação de todos. [...] De maneira que, para nós homens, o outro não é apenas o adversário a ser violentado para ser informado, mas também o aliado que informa junto conosco. Por certo: tal lembrança primordial vai caindo no esquecimento sob o impacto da cultura de massa. Mas continua presente, e pode evitar que nos transformemos em herdeiros e transmissores de informação programada. (FLUSSER; BEC, 2011, p. 122-123).

Novamente, Nobrow é justamente essa confluência de informações, de influências globalizada que é possível em virtude da colaboração, da aliança de diversos indivíduos na luta mencionada. Toda reserva, toda aversão acerca do Nobrow é consequência dessa lembrança primordial que pode impedir seu avanço, sua evolução. 


\section{A emergência do Vampyroteuthis e do Nobrow}

$\mathrm{O}$ mundo no qual vivemos tem a simetria de espelhos contrapostos. Tudo em tal mundo se reflete. Tal simetria é consequência do estar-no-mundo humano. O homem reflete no mundo, e o mundo, no homem, e este vaivém de contraposições refletidas é a própria realidade humana. [...] O Vampyroteuthis $[. .$.$] habita todas as nossas pro-$ fundidades, e nós os habitamos. E este encontro de si próprio no outro extremo do mundo é o derradeiro propósito de todas as explorações humanas. Porque "no fundo", o único tema do homem é o homem. (FLUSSER; BEC, 2011, p. 126).

Flusser discorre sobre o fato de que o Vampyroteuthis vem emergindo, como sob a forma do pensamento programado da cibernética previamente discutido. Mas coloca que sua emergência inesperada tem efeito de bomba.

O equilíbrio necessário seria o de expedições científicas que assumam a carga dos sonhos, dos desejos e dos receios que caracterizam a existência humana. Mas o espírito científico moderno se despoja precisamente desse tipo de carga: quer-se despreconcebido e objetivo. Por isso, o Vampyroteuthis que tais expedições científicas pescarão na profundidade do mar da China ou na do próprio pescador não será o nosso antípoda vivo e palpitante, mas um cadáver de espécime cuidadosamente preparado pelos métodos mais avançados da pesquisa [...].
É preciso contar fábulas nas quais o Vampyroteuthis pode agir a fim de poder alterar-nos. [...] Devem ser "ciências fictícias", isto é: superações da objetividade científica a serviço de um conhecimento concretamente humano. (FLUSSER; BEC, 2011, p. 130-131).

Essa é a fórmula do autoconhecimento humano espelhada no Vampyroteuthis proposta pelo autor. Afinal, o Vampyroteuthis não é educável e humanizável, o Vampyrtoteuthis emerge e o homem afunda. Humanizar o Vampyroteuthis implica vampyroteuthizar o homem. "Salvar" o Vampyroteuthis implica "perder" o homem (FLUSSER; BEC, 2011, p. 128). Flusser também conclui dessa maneira não poder haver algum tipo de síntese "homem-Vampyroteuthis", conclui que o resultado do encontro dos dois sempre resultará em híbrido, no qual é libertado o Vampyroteuthis no homem, e o homem no Vampyroteuthis. É tal espetáculo monstruoso que assistimos, toda vez que o Vampyroteuthis emerge (FLUSSER; BEC, 2011, p. 129).

O Vampyroteuthis vai surgindo como nosso próprio espelho. Como antípoda nosso, no qual todos os nossos aspectos são invertidos. Pois contemplar tal espelho, a fim de reconhecer-se nele, e a fim de poder alterar-se graças a tal reconhecimento, é o propósito de toda fábula, inclusive desta. (FLUSSER; BEC, 2011, p. 134).

E somente assim poderemos compreender verdadeiramente tanto o Vampyroteuthis quanto o Nobrow, não analisando fria e 
objetivamente dentro de um laboratório de acordo com as nossas ferramentas científicas vigentes. Nobrow é um fenômeno mundial, consequência da falta de aplicabilidade das antigas divisões da cultura em highbrow e lowbrow, da defasagem de sentido e de termos. Não podemos tatear concretamente o
Nobrow, colocá-lo em nossas mãos e analisá-lo materialmente, da mesma maneira que, se o fizermos com o Vampyroteuthis, também não o entenderemos verdadeiramente. Apenas apreenderemos a verdadeira natureza do Vampyroteuthis e do Nobrow se mergulharmos em seus abismos.

\section{Referências bibliográficas}

ANTUNES, Janaína Quintas. Nobrow: o inclassificável internacionalizado. São Paulo: Gênio Criador, 2020.

FLUSSER, Vilém; BEC, Louis. Vampyroteuthis Infernalis. São Paulo: Annablume, 2011.

SEABROOK, John. Nobrow: the culture of marketing, the marketing of culture. New York: Vintage Books, 2001.

SWIRSKI, Peter. From lowbrow to nobrow. Montreal: Mcgills Queens University Press, 2005.

TRIVINHO, Eugênio. O bunker glocal e seu paradoxo. São Paulo: Revista Galáxia, 2008.

Data da submissão: 29/05/2020

Data do aceite: 03/07/2020

Dados da autora:

\section{Janaina Quintas Antunes}

http://lattes.cnpq.br/5320610728310112

Doutora em Comunicação e Semiótica - PUC/SP; Mestre em Educação, Arte e História da Cultura - Mackenzie/SP. Presidenta da ABCiber (2019-2021) e professora da Universidade Anhembi Morumbi (UAM). E-mail: tcheina@ hotmail.com 
